\title{
Scoliosis-Specific exercises can reduce the progression of severe curves in adult idiopathic scoliosis: a long-term cohort study
}

Alessandra Negrini ${ }^{1}$, Maria Gabriella Negrini ${ }^{2}$, Sabrina Donzelli ${ }^{1 *}$, Michele Romano $^{1}$, Fabio Zaina ${ }^{1}$ and Stefano Negrini $i^{3,4}$

\begin{abstract}
Background: Scoliosis fusion surgery is generally considered the only means to stop the progression of adult idiopathic scoliosis (ADIS), but for patients refusing surgery there is lack of evidence in favour of conservative treatment. The aim of the present study was to verify the possible effectiveness of scoliosis-specific exercises when facing ADIS progression.

Methods: We designed a retrospective cohort study. We included $34 \mathrm{ADIS}$ patients in treatment at our Institute (5 males and 29 females, mean age was $38.0 \pm 11.0$ ), exclusively treated with specific Scoliosis Specific SEAS exercises.

Instrumentation: SEAS exercises are scoliosis-specific exercises. In adult patients they are aimed to recover postural collapse, postural control and vertebral stability through an active self-correction. Postural integration is a key element, including the neuromotor integration of correct postures and an ergonomic education program. Therapy includes at least two weekly exercise sessions each lasting $45 \mathrm{~min}$.

Outcome measures: Radiographic progression was the main outcome and it was analysed as a continuous variable. Statistics: One way ANOVA and paired t-test were applied for continuous data, while chi-square test was applied for categorical data. Alpha was set at 0.05 .

Results: The mean Cobb angle of the patients included into the present study, was $55.8 \pm 13.2^{\circ}$. Fifteen patients had previous $x$-rays testifying scoliosis progression: the average curve progression (worsening) was $9.8 \pm 6.6^{\circ}$ at a median of 25 (range 17-48) years. The remaining were characterized by more severe curves, exceeding $40^{\circ} \mathrm{Cobb}$ (mean curvature $50.9 \pm 13.6$ ) but it was not possible to prove that the curves had progressed in these cases. After an average period of 2 years of treatment (range 1-18y), $68 \%$ of the patients experienced an improvement in their scoliosis. However in one patient ( $3 \%$ ) the scoliosis worsened by $5^{\circ}$ in 18 years (progression rate reduced from $0.5^{\circ}$ to $0.27^{\circ}$ per year). Patients improved $4.6 \pm 5.0^{\circ} \mathrm{Cobb}(\mathrm{P}<0.05)$, with no differences based on the localization of the curve, gender, age, length of treatment, Cobb degrees at the start of observation or treatment.
\end{abstract}

Conclusions: Scoliosis Specific SEAS Exercises proved to be superior to natural history in ADIS, at least in individual cases and should be considered as a first line treatment especially in patients refusing scoliosis surgery.

\footnotetext{
* Correspondence: sabrina.donzelli@isico.it

${ }^{1}$ ISICO (Italian Scientific Spine Institute), Via R. Bellarmino 13/1, Milan 20141, Italy

Full list of author information is available at the end of the article
} 


\section{Background}

It has long been known (since 1969) that idiopathic scoliosis can continue to progress during adulthood after skeletal maturity [1]. Its evolution is slow and insidious and involves both the anatomic and the functional aspect of the curve development or the worsening of painful spinal or radicular symptoms and/or decompensation [2]. Once asymmetric load or degeneration occurs, the pathomorphology and pathomechanism in adult idiopathic scoliosis (ADIS) is quite predictable. Asymmetric degeneration leads to increased asymmetric loading and therefore to a progression of the degeneration and deformity [3].

More than $60 \%$ of cases of ADIS progress, particularly the curves exceeding $30^{\circ} \mathrm{Cobb}$ at skeletal maturity, regardless of the curve pattern $[4,5]$. Marty-Poumarat [6] showed that the rate of progression in ADIS is linear, and it can be used to establish an individual prognosis. This rate of progression is deemed to be around $0.5-1^{\circ}$ per year $[3,6]$; together with the known radiographic measurement error, recognised in $5^{\circ}[7,8]$, this drives to the consequence that individual variations can rarely be ruled out before some years of observation.

Different types of treatment are available: scoliosis specific exercises, various type of spinal orthesis, soft or rigid and surgery. Surgery is generally considered to be the only intervention that can stop curve progression, while scoliosis specific exercises and orthesis are mainly considered for pain control $[3,4]$. In the literature, the prevailing treatment is surgery [3]; but scoliosis specific exercises together with other type of physical treatment, such as manipulation program, has also been proposed to avoid or stop curve progression [11, 12]. In a shortterm case series Weiss et al. showed $43.93 \%$ of 107 patients improved 5 or more Cobb degrees immediately after 4-6 weeks of in-patient exercise program [9]. Morningstar et al. showed that 19 patients treated with spinal manipulation and various physiotherapic procedures reported immediately after the therapy an average correction of $17^{\circ} \mathrm{Cobb}$ [10]. In a case report, Negrini A et al. showed a $18.5 \mathrm{Cobb}$ degrees reduction after one year of Scoliosis Specific SEAS exercises [13].

In Italy there is a long tradition of specific exercise prescription for idiopathic scoliosis, with recently proven results in adolescents [14-18]; when ADIS patients decide to try and avoid surgery, scoliosis-specific exercises have been proposed for many years at our centre. It is very important to investigate the evidence regarding different conservative alternatives within a reasonable timeframe. The aim of this study was to retrospectively review all the ADIS patients in treatment in our Institute, to ascertain the effectiveness of a scoliosis-specific exercise treatment that might limit the progression of severe curves in idiopathic adult scoliosis patients.

\section{Methods}

\section{Study design}

This was a retrospective cohort study, including all the ADIS patients in treatment in our Institute with Scoliosis Specific SEAS Exercises until October 2008.

\section{Participants}

Inclusion criteria were: adults (18 years or more and Risser 5 stage achieved) with ADIS larger than $30^{\circ}$ and documented curve progression during adulthood (at least $\left.6^{\circ} \mathrm{Cobb}\right)$ or larger than $40^{\circ}$ who had refused surgical treatment. Patients were prescribed Scoliosis Specific SEAS Exercises exclusively. Patients were assessed a minimum of 1 year after their first assessment. All patients had to practice their exercises regularly for at least ten months per year; X-rays after one year of therapy at least. De-novo scoliosis and fused patients were excluded [3].

We included two sub-groups of patients: one group included demonstrated progression (PP), the other group had high degree scoliosis but with no definitive proof of progression apart from the patients' declaration (nPP). In both cases, patients adhered to treatment actively, declaring their willingness to try and avoid fusion.

\section{Outcome measures}

To evaluate the effect of treatment, we considered the last available $\mathrm{x}$-ray for each single patient. All $\mathrm{x}$-rays were blindly measured twice by the same expert physician (SN) and the worst result was considered: in a previous study his repeatability error proved to be less than $3^{\circ}$ Cobb [19].

Moreover, patients were categorized as unchanged, worsened, or improved according to both the intra-rater repeatability for Cobb angles measurements of the expert involved [20] and the classical $5^{\circ}$ limits [8]. We considered results both in terms of the most important curve of each single patient as well as in terms of the mean of the curves included. We deemed patients changed if at least one of their curve's progressed or improved. Statistical analysis: After applying the Shapiro-Wilks test to check for normality, one way ANOVA and paired $t$-test were applied for continuous data, while chi-square test was applied for categorical data. Alpha was set at 0.05 .

\section{Results}

Populations: 34 patients ( 29 females, 5 males; mean age $38.0 \pm 11.0$ years) out of 381 patients from our database fulfilled the inclusion criteria and were included in this study. Curves' type rates are shown in Table 1.

The worst curves of the 34 patients measured $55.8 \pm$ $13.2^{\circ}$ Cobb; results are shown in Table 2, upper part.

A further analysis was performed to compare patients with demonstrated progression (PP group). Patients with 
Table 1 Curve's type in the sample of subjects considered

\begin{tabular}{llll}
\hline Curves type & & $\mathrm{N}$ & $\%$ \\
\hline Single curve & TH & 4 & $12 \%$ \\
$\mathrm{~N}=14$ & $\mathrm{TH}-\mathrm{L}$ & 4 & $12 \%$ \\
$\%=41.2 \%$ & $\mathrm{LU}$ & 6 & $17 \%$ \\
Double curve & $\mathrm{TH}+\mathrm{L}$ & 17 & 50 \\
$\mathrm{~N}=20$ & $\mathrm{TH}+\mathrm{TH}-\mathrm{L}$ & 1 & 3 \\
$\%=58.8 \%$ & TH DOUBLE MAJOR & 2 & 6 \\
\hline
\end{tabular}

severe curves, but without $\mathrm{x}$-ray evidence of progression (nPP group): fifteen patients were prescribed exercise since they had a progression of $9.8 \pm 6.6^{\circ}$ Cobb during an average period of 25 years (range 17-48), but their curves were below $40^{\circ} \mathrm{Cobb}$ (PP group); while 19 patients with curves over $40^{\circ}$ who decided to try to prevent progression with exercises belonged to then PP sub-group.

At the start of treatment, the average and worst curves did not show any overall difference among subgroups (Table 2); we found significant differences only for the Thoracolumbar curves magnitude in PP and nPP groups (61.5 \pm 6.4 and $40.6 \pm 7.8$ respectively); regarding curves type in the PP subgroup there was a significantly higher rate of double curves and Lumbar curves (12 vs 5).

After 2 years of therapy (range 1-18 years) $74 \%$ of patients improved over the measurement error of $3^{\circ}$, while $6 \%$ (2 patients) progressed (Fig. 1); considering the "classical" threshold of $5^{\circ}$ these percentages were $68 \%$ and $3 \%$ (1 patient) respectively (Table 3 ). In the nPP group there was a tendency toward better results (81 \% improved and $5 \%$ progressed vs $67 \%$ and $7 \%$ respectively, $\mathrm{p}=0.07$ ); we did not find any difference in terms of improvement/progression according to the localization of the curve, while there were differences among subgroups, mainly considering the $3^{\circ}$ limits (Table 3).
The two patients who progressed (one per subgroup) had the following characteristics: in PP, one male with a Thoracic double major curve that started treatment at 28 years of age because of a previous progression in 8 years (from $52^{\circ}-54^{\circ}$ to $52^{\circ}-58^{\circ}$; rate of $0.5^{\circ}$ per year): in the following 18 years of treatment he progressed to $57^{\circ}-62^{\circ}$ (rate of $0.22-0.27^{\circ}$ per year); in nPP, one female with a double thoracic and lumbar curve who started at 51 years and progressed in 5 years from $40^{\circ}-38^{\circ}$ to $41^{\circ}-41^{\circ}$.

All curves improved for all localizations, even if the less numerous groups (5 thoracolumbar curves, and 2 proximal thoracic) did not reach statistical significance; we did not find any statistical difference among groups for these results (Table 2).

We also did not find any statistically significant differences according to gender and age. Time is correlated with Cobb degree progression before the start of scoliosis specific exercises, while after the beginning of the treatment this correlation is lost.

We also included 5 patients who re-started treatment after an interruption of 6 years (range 3-10): in this period they had worsened from a minimum of $3^{\circ}$ in 3 years to a maximum of $13^{\circ}$ in 8 years. Two of them had a follow-up x-ray after the new period of Scoliosis Specific Exercises: one patient, previously progressed $8^{\circ}$ in 10 years during the interruption, reduced the curvature of $8^{\circ}$ in 9 years of exercises; the other, previously worsened $10^{\circ}$ in 7 years, worsened $5^{\circ}$ more in 21 years of treatment.

\section{Discussion}

The present cohort study confirmed that when patients with adult scoliosis progress, Scoliosis Specific Exercises can be effective to obtain stability and in some cases to reduce the Cobb angles in degrees. In highly progressive curves, exercises appear to slow down the progression of the curvature (worsening). In addition, this study gives

Table 2 Left part: Cobb degrees comparison in all participants and in the two subgroups considered. Right part: results according to curves' type

\begin{tabular}{|c|c|c|c|c|c|c|c|c|c|c|c|c|c|c|c|c|c|}
\hline & & \multicolumn{6}{|c|}{ Patients } & \multicolumn{10}{|c|}{ Curves } \\
\hline & & \multicolumn{2}{|c|}{ Age (yy.mm) } & \multicolumn{2}{|c|}{ Worst } & \multicolumn{2}{|c|}{ Average } & \multicolumn{2}{|c|}{ Total } & \multicolumn{2}{|c|}{ Proximal thoracic } & \multicolumn{2}{|c|}{ thoracic } & \multicolumn{2}{|c|}{ Thoracolumbar } & \multicolumn{2}{|c|}{ Lumbar } \\
\hline & & Pre & Post & Pre & Post & Pre & Post & Pre & Post & Pre & Post & Pre & Post & Pre & Post & Pre & Post \\
\hline \multirow[t]{3}{*}{ Total } & Average & 38.02 & 41.03 & 55,8 & 51,1 & 51,6 & 47,5 & 50,7 & 46,7 & 42,5 & 42,0 & 52,9 & 48,0 & 49,0 & 46,0 & 49,4 & 45,8 \\
\hline & Standard Deviation & 11.01 & 10.11 & 14,1 & 12,9 & 12,8 & 13,0 & 13,8 & 13,5 & 13,4 & 21,2 & 15,2 & 14,6 & 12,7 & 4,9 & 12,9 & 11,0 \\
\hline & $P$ & & & \multicolumn{2}{|c|}{$<0.001$} & \multicolumn{2}{|c|}{$<0.001$} & \multicolumn{2}{|c|}{$<0.001$} & \multicolumn{2}{|l|}{ NS } & \multicolumn{2}{|c|}{$<0.001$} & \multicolumn{2}{|l|}{ NS } & \multicolumn{2}{|c|}{$<0.001$} \\
\hline \multirow[t]{3}{*}{ PP } & Average & 40.04 & 44.02 & 55,1 & 50,6 & 52,5 & 48,2 & 50,4 & 46,2 & 42,5 & 42,0 & 54,2 & 49,6 & 61,5 & 57,5 & 44,8 & 40,3 \\
\hline & Standard Deviation & 10.10 & 10.11 & 13,2 & 14,4 & 13,4 & 12,4 & 13,5 & 13,7 & 13,4 & 21,2 & 15,4 & 16,0 & 6,4 & 12,3 & 9,8 & 12,8 \\
\hline & $P$ & & & \multicolumn{2}{|c|}{$<0.005$} & \multicolumn{2}{|c|}{$<0.005$} & \multicolumn{2}{|c|}{$<0.001$} & \multicolumn{2}{|l|}{ NS } & \multicolumn{2}{|c|}{$<0.05$} & \multicolumn{2}{|l|}{ NS } & \multicolumn{2}{|l|}{$<0.05$} \\
\hline \multirow[t]{3}{*}{ nPP } & Average & 36.06 & 38.11 & 56,3 & 51,6 & 50,8 & 46,9 & 50,9 & 47,0 & - & - & 52,0 & 46,9 & 40,7 & 38,3 & 51,9 & 48,8 \\
\hline & Standard Deviation & 12.04 & 12.03 & 14,1 & 14,0 & 10,7 & 10,4 & 13,6 & 13,5 & - & - & 16,9 & 15,8 & 7,8 & 7,8 & 10,5 & 11,0 \\
\hline & $P$ & & & \multicolumn{2}{|c|}{$<0.001$} & \multicolumn{2}{|c|}{$<0.001$} & \multicolumn{2}{|c|}{$<0.001$} & \multicolumn{2}{|l|}{-} & \multicolumn{2}{|c|}{$<0.001$} & \multicolumn{2}{|l|}{ NS } & \multicolumn{2}{|l|}{$<0.01$} \\
\hline P amo & ng sub-groups & NS & NS & NS & NS & NS & NS & NS & NS & & & NS & NS & $<0.05$ & NS & NS & NS \\
\hline
\end{tabular}




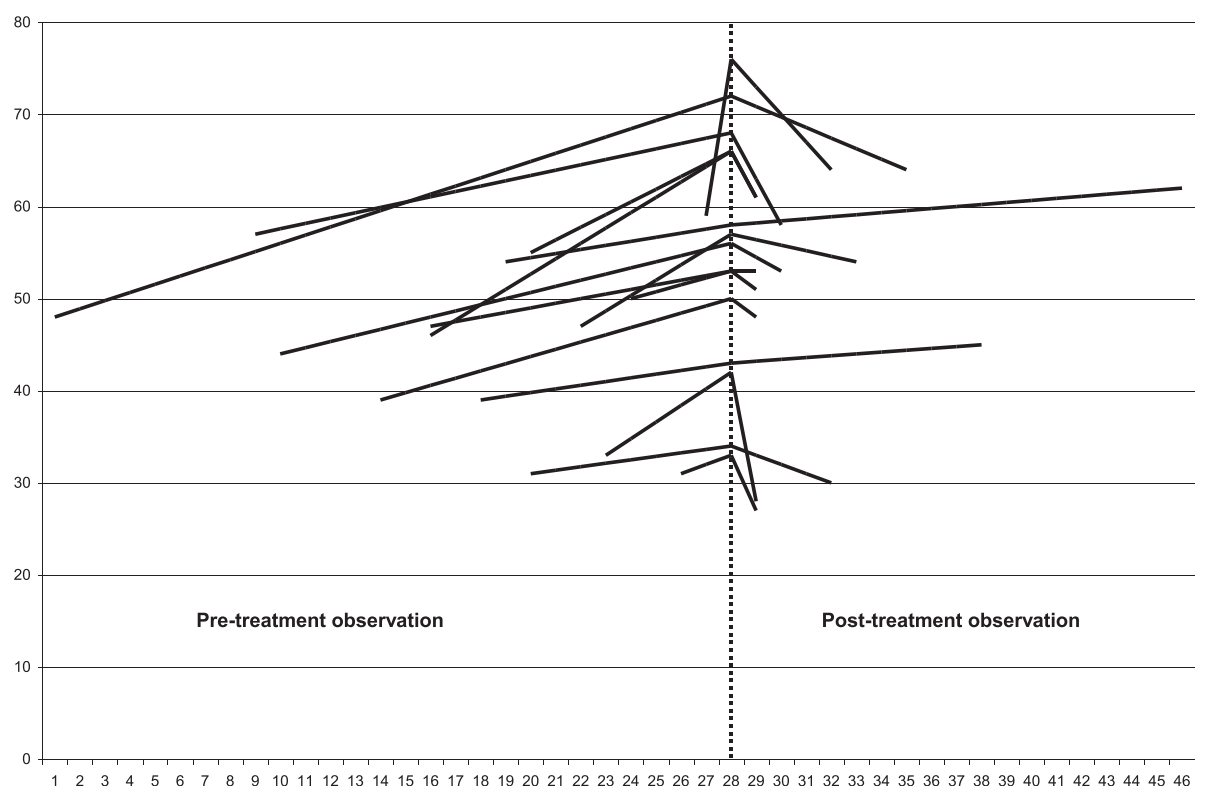

Fig. 1 Results after about 2 years of therapy, according to the $3^{\circ}$ Cobb degrees measurement error

preliminary insight to the fact that continuity and consistency in Scoliosis Specific Exercises is mandatory, in order to not lose any improvements in results. For what concerns the analysis in the two subgroups PP, and $\mathrm{nPP}$, the two groups were different in terms of curve morphology at start, and this could have affected the results. This may be one of the reasons for the tendency toward better results in the nPP sub-group. Nevertheless, the patients belonging to the nPP group, had more severe curves, usually considered good candidates to fusion independently from proven progression or not [3].

The interpretation of the results for the nPP group and the whole population could be considered as potentially biased, since these patients were stables when they entered the treatment. Moreover the pattern of curves was slightly different from the one described in long term follow up of scoliosis [21]. Nevertheless, since most of the patients improved, we considered this a valuable result.

There is an important question coming out from these results of improvement: how is it possible through "simple" scoliosis-specific exercises to obtain the reduction of scoliosis in ADIS? We do not have answers, but we do have a reasonable hypothesis. Duval-Beaupère [22] described the case of three different radiographs that, made at the same time in the same scoliosis patients, resulted in a curve magnitude that progressively decreased: standing (SR), lying down (LR) and in correction e.g. using a cast (CR) (Fig. 2). While only CR gives the fixed, not corrigible osteo-ligamentous deformity,

Table 3 Results expressed in rate of improved, stabilized or progressed, based on the $5^{\circ}$ Cobb threshold, promoted by the SRS

\begin{tabular}{|c|c|c|c|c|c|c|c|c|c|c|c|c|c|c|c|c|c|}
\hline & & \multicolumn{6}{|c|}{ Patients } & \multicolumn{10}{|c|}{ Curves } \\
\hline & & \multicolumn{2}{|c|}{ At least one curve } & \multicolumn{2}{|l|}{ Worst } & \multicolumn{2}{|c|}{ Average } & \multicolumn{2}{|l|}{ Total } & \multicolumn{2}{|c|}{ Proximal thoracic } & \multicolumn{2}{|c|}{ Thoracic } & \multicolumn{2}{|c|}{ Thoracolumbar } & \multicolumn{2}{|c|}{ Lumbar } \\
\hline & & 3 & 5 & 3 & 5 & 3 & 5 & 3 & 5 & 3 & 5 & 3 & 5 & 3 & 5 & 3 & 5 \\
\hline \multirow[t]{3}{*}{ Total } & Improved & $74 \%$ & $68 \%$ & $65 \%$ & $50 \%$ & $68 \%$ & $47 \%$ & $57 \%$ & $56 \%$ & $50 \%$ & $50 \%$ & $63 \%$ & $54 \%$ & $60 \%$ & $40 \%$ & $52 \%$ & $48 \%$ \\
\hline & Stable & $19 \%$ & $29 \%$ & $32 \%$ & $48 \%$ & $29 \%$ & $53 \%$ & $37 \%$ & $44 \%$ & $0 \%$ & $0 \%$ & $33 \%$ & $46 \%$ & $40 \%$ & $60 \%$ & $43 \%$ & $52 \%$ \\
\hline & Progressed & $6 \%$ & $3 \%$ & $3 \%$ & $2 \%$ & $3 \%$ & $0 \%$ & $6 \%$ & $0 \%$ & $50 \%$ & $50 \%$ & $4 \%$ & $0 \%$ & $0 \%$ & $0 \%$ & $4 \%$ & $0 \%$ \\
\hline \multirow[t]{3}{*}{ PP } & Improved & $67 \%$ & $53 \%$ & $67 \%$ & $47 \%$ & $67 \%$ & $47 \%$ & $64 \%$ & $50 \%$ & $50 \%$ & $50 \%$ & $60 \%$ & $50 \%$ & $100 \%$ & $50 \%$ & $63 \%$ & $50 \%$ \\
\hline & Stable & $27 \%$ & $40 \%$ & $27 \%$ & $53 \%$ & $27 \%$ & $53 \%$ & $27 \%$ & $45 \%$ & $0 \%$ & $0 \%$ & $30 \%$ & $50 \%$ & $0 \%$ & $50 \%$ & $38 \%$ & $50 \%$ \\
\hline & Progressed & $7 \%$ & $7 \%$ & $7 \%$ & $0 \%$ & $7 \%$ & $0 \%$ & $9 \%$ & $5 \%$ & $50 \%$ & $50 \%$ & $10 \%$ & $0 \%$ & $0 \%$ & $0 \%$ & $0 \%$ & $0 \%$ \\
\hline \multirow[t]{3}{*}{$n P P$} & Improved & $81 \%$ & $81 \%$ & $63 \%$ & $63 \%$ & $68 \%$ & $47 \%$ & $53 \%$ & $50 \%$ & - & - & $64 \%$ & $57 \%$ & $33 \%$ & $33 \%$ & $47 \%$ & $47 \%$ \\
\hline & Stable & $13 \%$ & $19 \%$ & $37 \%$ & $37 \%$ & $32 \%$ & $53 \%$ & $44 \%$ & $50 \%$ & - & - & $36 \%$ & $43 \%$ & $67 \%$ & $67 \%$ & $47 \%$ & $53 \%$ \\
\hline & Progressed & $6 \%$ & $0 \%$ & $0 \%$ & $0 \%$ & $0 \%$ & $0 \%$ & $3 \%$ & $0 \%$ & - & - & $0 \%$ & $0 \%$ & $0 \%$ & $0 \%$ & $7 \%$ & $0 \%$ \\
\hline \multicolumn{2}{|c|}{ Chi square } & $<0.05$ & $<0.001$ & $<0.05$ & $<0.05$ & $<0.05$ & NS & $<0.05$ & NS & NA & NA & $<0.005$ & NS & NA & NA & $<0.01$ & NS \\
\hline
\end{tabular}




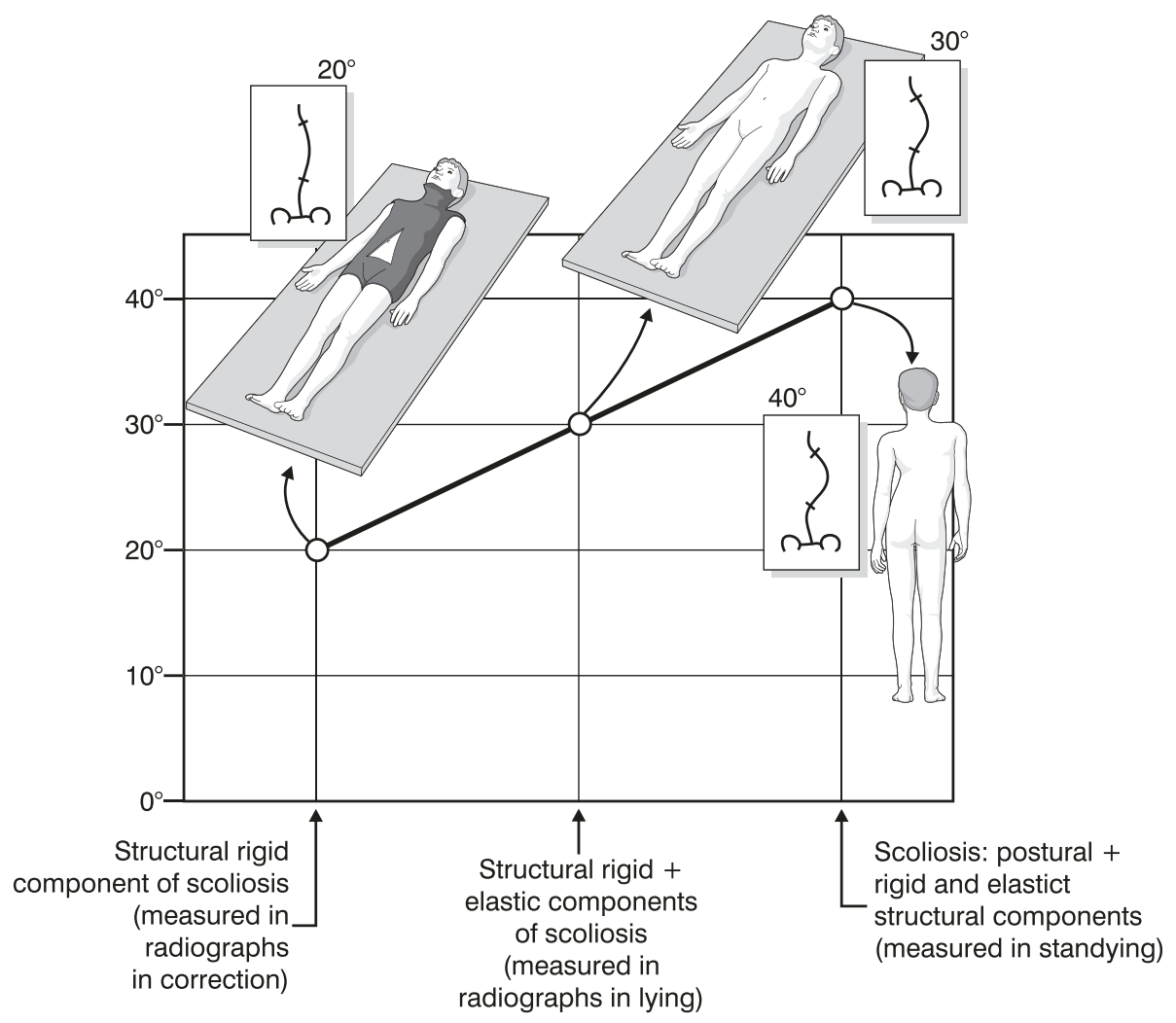

Fig. 2 The postural component of scoliosis [19]. A scoliosis curve is made of many different components, including a postural one. DuvalBeaupére [19] described the case of three different radiographs: standing (SR), lying down (LR) and in correction e.g. using a cast (CR). The structural bony component can be measured with the $C R$; the structural ligamentous component comes from the difference between $L R$ and $C R$; the postural component from the difference between SR and LR

the author describes the difference between SR and LR as a "postural collapse" that is the difference between the LR and CR values is seen as the "reducibility" due to concave ligament stretching. In other words, the classical SR gives the entire scoliosis, made up of some components including a postural one. This has also been quantified: in adolescents, regardless of curve magnitude. The mean difference between a standing radiograph and a supine one has been quantified as $9^{\circ}$ Cobb [23], or around $20 \%$ [24]. In ADIS it has been shown that in severe curves (mean Cobb angle: 60 degrees) performing an x-ray at different hours of the day [25] can give a measurement error due to the worsening of the curve as the days goes by ie from the morning to the evening: this can easily be attributed to the postural collapse of the spine. Accordingly, while the described reduction of scoliotic curve through SS exercises is certainly not due to a reduction of the bone deformity, it could easily be attributed or explained as the activity of the specific muscle acting either against gravity in standing or with gravity eliminated in lying down and a consequent recovery of the postural collapse, which is present in upright posture [26].
An anti-gravity correction can result in a long term achievement mainly through biomechanical means. While in adolescents a better growth of the vertebrae is allowed [27], in adults the process involved is bony progressive deformation due to degeneration. In ADIS postural collapse can have a role in enhancing progression, in the long term, due to the chronic asymmetric increase of compression. On the other hand, the reduction of the postural collapse (that is congruent with the reduction of the standing $\mathrm{x}$-ray in the short term) can reduce asymmetric degeneration and consequently ADIS curve progression. Obviously, the increased quality of movement together with the biomechanical changes of the spinal soft tissues could play a role in decreasing the risk of progression $[27,28]$. In conclusion when considering the importance of sagittal balance and its correlation with pain and disability [29-33] these results suggest that Scoliosis Specific Exercises can play a significant role in the management of patients with IS. Scoliosis Specific Exercises may enhance the possibility of compensation, thus preventing the loss of sagittal balance typical of the progression of scoliosis. |From this perspective, Scoliosis Specific Exercises could be effective in decreasing pain and disability 
resulting in an increased quality of life. It is hoped that future in depth studies will explore and analyse this important outcomes further. This cohort study opens up a new perspective to the approach to ADIS, particularly of patients that appear to progress. Instead of a fatalistic "wait and see" approach, an active one could be considered in the attempt to postpone, and eventually avoid surgery.

Even though this study presents a low level of evidence, current literature confirms the very short term effect of Scoliosis Intensive Rehabilitation (SIR) [9], SS exercises [13] and also manipulations [10, 11, 26]. In addition one case report showed good long term results with a multimodal treatment - exercises together with manipulative medicine [12]. Literature is however still lacking studies that compare different kind of Scoliosis Specific Exercises. Therefore in order to fill the gap in knowledge more studies are needed. Considering the very important challenges of conducting Scoliosis Specific Exercise RCT's it is clear the importance of evidence of a lower level is needed to increase the knowledge base. From this point of view the main strength of the present study are the long term results, in a carefully selected population, that allows some inferences regarding Scoliosis Specific Exercise effectiveness to stop or reduce progression in adult scoliosis. The long period of follow up, limited the sample size; the convenience sampling is another limit that can affect results. In particular we can hypothesize that only patients refusing surgery and with an attitude towards the acceptance of actually doing the Scoliosis Specific exercises were included in this cohort which is a factor that can affect generalizability.

\section{Conclusion}

Exercises proved to be superior to natural history in ADIS, and should be considered a possible tool for curve control. Future larger, long term, observational studies, should focus on defining the best Scoliosis Specific Exercises management approach and explore other very important issues associated with adult progressive spinal deformities, such as, sagittal global balance, back pain, disability and quality of life.

\section{Competing interests}

The authors declare that they have no competing interests.

\section{Authors' contributions}

All the authors contributed equally to this study. All authors read and approved the final manuscript.

\section{Author details}

'ISICO (Italian Scientific Spine Institute), Via R. Bellarmino 13/1, Milan 20141, Italy. ${ }^{2}$ Centro Fisioterapia Negrini, Vigevano, Italy. ${ }^{3}$ Department of Clinical and Experimental Sciences, University of Brescia, Brescia, Italy. ${ }^{4}$ IRCCS Fondazione Don Gnocchi, Milan, Italy.

Received: 9 December 2014 Accepted: 16 June 2015

Published online: 11 July 2015

\section{References}

1. Collis DK, Ponseti IV. Long-term follow-up of patients with idiopathic scoliosis not treated surgically. J Bone Joint Surg Am. 1969;51(3):425-45.

2. Guigui P, Rillardon L. Adult spinal deformities. Rev Prat. 2006;56(7):701-8

3. Aebi M. The adult scoliosis. Eur Spine J Off Publ Eur Spine Soc Eur Spinal Deform Soc Eur Sect Cerv Spine Res Soc. 2005;14(10):925-48.

4. Weinstein SL, Dolan LA, Spratt KF, Peterson KK, Spoonamore MJ, Ponseti IV. Health and function of patients with untreated idiopathic scoliosis: a 50-year natural history study. JAMA, J Am Med Assoc. 2003;289(5):559-67.

5. Weinstein SL. Natural history. Spine. 1999;24(24):2592-600.

6. Marty-Poumarat C, Scattin L, Marpeau M, Garreau De Loubresse C, Aegerter P. Natural history of progressive adult scoliosis. Spine. 2007;32(11):1227-34. discussion 1235

7. Zmurko MG, Mooney JF, Podeszwa DA, Minster GJ, Mendelow MJ, Guirgues A. Inter- and intraobserver variance of Cobb angle measurements with digital radiographs. J Surg Orthop Adv. 2003;12(4):208-13.

8. Richards BS, Bernstein RM, D'Amato CR, Thompson GH. Standardization of criteria for adolescent idiopathic scoliosis brace studies: SRS Committee on Bracing and Nonoperative Management. Spine. 2005;30(18):2068-75. discussion 2076-7

9. Weiss HR. Influence of an in-patient exercise program on scoliotic curve. Ital J Orthop Traumatol. 1992;18(3):395-406.

10. Morningstar MW, Woggon D, Lawrence G. Scoliosis treatment using a combination of manipulative and rehabilitative therapy: a retrospective case series. BMC Musculoskelet Disord. 2004:5:32.

11. Tarola GA. Manipulation for the control of back pain and curve progression in patients with skeletally mature idiopathic scoliosis: two cases. J Manipulative Physiol Ther. 1994;17(4):253-7.

12. Brooks WJ, Krupinski EA, Hawes MC. Reversal of childhood idiopathic scoliosis in an adult, without surgery: a case report and literature review. Scoliosis. 2009;4:27.

13. Negrini A, Parzini S, Negrini MG, Romano M, Atanasio S, Zaina F, et al. Adult scoliosis can be reduced through specific SEAS exercises: a case report. Scoliosis. 2008;3:20.

14. Zaina F, Negrini S, Atanasio S, Fusco C, Romano M, Negrini A. Specific exercises performed in the period of brace weaning can avoid loss of correction in Adolescent Idiopathic Scoliosis (AIS) patients: Winner of SOSORT's 2008 Award for Best Clinical Paper. Scoliosis. 2009:4:8.

15. Negrini S, Negrini A, Romano M, Verzini N, Negrini A, Parzini S. A controlled prospective study on the efficacy of SEAS.02 exercises in preventing progression and bracing in mild idiopathic scoliosis. Stud Health Technol Inform. 2006;123:523-6.

16. Negrini S, Zaina F, Romano M, Negrini A, Parzini S. Specific exercises reduce brace prescription in adolescent idiopathic scoliosis: a prospective controlled cohort study with worst-case analysis. J Rehabil Med. 2008;40(6):451-5.

17. Negrini S, Negrini A, Romano M, Verzini N, Negrini A, Parzini S. A controlled prospective study on the efficacy of SEAS.02 exercises in preparation to bracing for idiopathic scoliosis. Stud Health Technol Inform. 2006;123:519-22

18. Negrini S, Atanasio S, Zaina F, Romano M. Rehabilitation of adolescent idiopathic scoliosis: results of exercises and bracing from a series of clinical studies. Europa Medicophysica-SIMFER 2007 Award Winner. Eur J Phys Rehabil Med. 2008;44(2):169-76.

19. Negrini A., Romano M.A. blind radiographic controlled study on efficacy of Active self correction according to SEAS.02 3rd International Conference on conservative management of spinal deformities 2006, Poznan (Poland).

20. Weinstein SL. Idiopathic scoliosis. Natural history. Spine. 1986;11(8):780-3

21. Duval-Beaupère $G$, Lespargot A, Grossiord A. Flexibility of scoliosis. What does it mean? Is this terminology appropriate? Spine. 1985;10(5):428-32.

22. Torell G, Nachemson A, Haderspeck-Grib K, Schultz A. Standing and supine Cobb measures in girls with idiopathic scoliosis. Spine. 1985;10(5):425-7.

23. Zetterberg C, Hansson T, Lindström J, Irstam L, Andersson GB. Postural and time-dependent effects on body height and scoliosis angle in adolescent idiopathic scoliosis. Acta Orthop Scand. 1983;54(6):836-40.

24. Beauchamp M, Labelle H, Grimard G, Stanciu C, Poitras B, Dansereau J. Diurnal variation of Cobb angle measurement in adolescent idiopathic scoliosis. Spine. 1993;18(12):1581-3.

25. Stokes IAF, Burwell RG, Dangerfield PH, IBSE. Biomechanical spinal growth modulation and progressive adolescent scoliosis-a test of the "vicious cycle" pathogenetic hypothesis: summary of an electronic focus group debate of the IBSE. Scoliosis. 2006;1:16. 
26. Romano M, Negrini S. Manual therapy as a conservative treatment for adolescent idiopathic scoliosis: a systematic review. Scoliosis. 2008;3:2.

27. De Mauroy JC. Idiopathic scoliosis and chaos. Stud Health Technol Inform. 2008; $135: 53-7$.

28. Mac-Thiong J-M, Roussouly P, Berthonnaud E, Guigui P. Sagittal parameters of global spinal balance: normative values from a prospective cohort of seven hundred nine Caucasian asymptomatic adults. Spine. 2010;35(22):E1193-8.

29. Roussouly P, Nnadi C. Sagittal plane deformity: an overview of interpretation and management. Eur Spine J Off Publ Eur Spine Soc Eur Spinal Deform Soc Eur Sect Cerv Spine Res Soc. 2010;19(11):1824-36.

30. Roussouly P, Gollogly S, Berthonnaud E, Dimnet J. Classification of the normal variation in the sagittal alignment of the human lumbar spine and pelvis in the standing position. Spine. 2005;30(3):346-53.

31. Glassman SD, Bridwell K, Dimar JR, Horton W, Berven S, Schwab F. The impact of positive sagittal balance in adult spinal deformity. Spine. 2005;30(18):2024-9.

32. Schwab F, Lafage V, Patel A, Farcy J-P. Sagittal plane considerations and the pelvis in the adult patient. Spine. 2009;34(17):1828-33.

33. Negrini S. The evidence -based ISICO Approach to spinal deformities. 1st edition ed. ISICO: Milan, Boston; 2007.

\section{Submit your next manuscript to BioMed Central and take full advantage of:}

- Convenient online submission

- Thorough peer review

- No space constraints or color figure charges

- Immediate publication on acceptance

- Inclusion in PubMed, CAS, Scopus and Google Scholar

- Research which is freely available for redistribution 